\title{
Canadian health challenges: diabetes and disparity
}

- Cite as: CMAJ 2017 January 23;189:E126. doi: 10.1503/cmaj.109-5373

anada has rising rates of diabetes, low rates of immunization and health disparities between indigenous and nonindigenous Canadians. Despite this, $90 \%$ of Canadians say they are in "good to excellent health."

"Overall, Canadians are among the most healthy in the world," said Dr. Gregory Taylor, Canada's former chief public health officer (CPHO) at the Public Health Agency of Canada and author of the Dec. 15 report Health Status of Canadians 2016.

The best indicator of this is Canadians' high life expectancies, estimated for those born in 2017 to be 79 years for men and 83 for women. "However, there are some Canadians who are not sharing in this good health," Taylor said.

Indigenous men, for example, are projected to live for six fewer years than nonindigenous men, and indigenous women are expected to live five fewer years. Inuit men have a life expectancy of 64 years and women 73 years.

Indigenous peoples also bear a greater burden of disease. The rate of tuberculosis (TB) among Inuit, for instance, is almost 50 times higher than it is for nonInuit Canadians. In 2014, Indigenous peoples made up $4 \%$ of the population but accounted for $21 \%$ of all reported TB cases.

Disparity in income also appears to affect health. In 2014, Canadians with the lowest income were twice as likely to report living with cardiovascular disease as those with the highest income.

Taylor's report highlights several other areas of concern. Diabetes has nearly doubled from $6 \%$ in 2000 to $10 \%$ in 2011. Type 2 diabetes is linked to poor diet, low physical activity and higher rates of overweight and obesity, "all of which are associated with higher rates of other diseases and conditions," Taylor wrote.

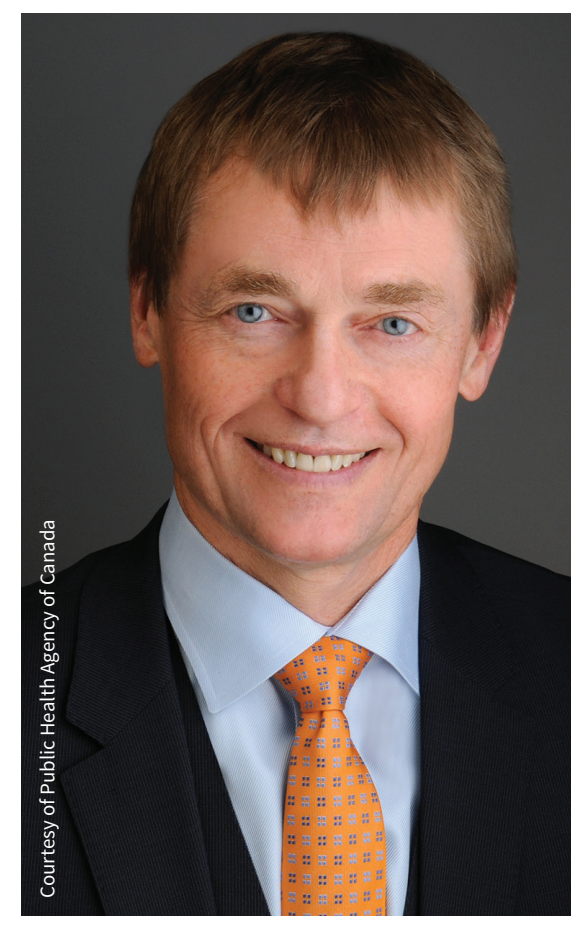

Dr. Gregory Taylor has issued his final health status report; he retired Dec. 16.

Canada also lags on immunization rates compared with other $\mathrm{G} 7$ countries, with the lowest rate of vaccinations among one-year-old children - $91 \%$ - for diphtheria, pertussis and tetanus (DPT). Among two-year-old children, only $77 \%$ have received the recommended four doses for DPT. In addition, only $90 \%$ of one-year-old children have been vaccinated for measles - the second lowest rate among $\mathrm{G} 7$ countries.

Immunization rates for measles and DPT now fall well below coverage goals of $97 \%$ by age two. Canada has so far had 11 reported cases of measles in 2016. This is a decrease from 2015, when 196 cases were reported in Canada, $87 \%$ of which were among unvaccinated individuals.

Among adults, $80 \%$ believe they have received their required vaccines, yet only
$6 \%$ were adequately covered for pertussis and tetanus.

Canada is investigating ways to boost vaccination rates, says Taylor, including looking to Newfoundland, which has one of the best track records in the country. Nurses there offer vaccinations to the parents each time they visit. "For some reason, it works," Taylor said. "It doesn't mean we should adopt that, but we need to look at those delivery models."

More broadly, Taylor said that environmental changes, including global warming, will affect Canadians health in the future. "We're seeing the effects of that already," he said, referring to the fact that mosquitoes that transmit Zika have been found in Canada.

"They have not been established in Canada, but with global warming, that might be a possibility - I don't mean to scare people, but that's a possibility."

Global warming has already created conditions conducive to the spread of Lyme disease and West Nile virus in Canada.

After two years as $\mathrm{CPHO}$, Taylor retired Dec. 16, though his term was expected to run five years. $\mathrm{He}$ is the second doctor to lead the Public Health Agency of Canada, which was created in 2004 following the SARS crisis. He followed Dr. David ButlerJones, who left in 2013 after suffering two strokes. Taylor was Butler-Jones' deputy for two years.

Taylor said he retired so he can hike, travel and ski. "If I'm lucky, I should have 10 to 15 years of good health."

"I also want to do a lot of volunteer work," he said. "Working at the national, federal level, you work through people and I don't get to work with Canadians directly very often."

Jay Rankin, CMAJ 